\title{
Lung function, radiological changes and exposure: analysis of ATSDR data from Libby, MT, USA
}

\author{
D. Weill*, G. Dhillon*, L. Freyder" J. Lefante ${ }^{*}$ and H. Glindmeyer ${ }^{*}{ }^{\dagger}$
}

ABSTRACT: In 2000, the Agency for Toxic Substances and Disease Registry (ATSDR; Atlanta, GA, USA) investigated lung disease in those exposed to the tremolite-contaminated vermiculite mine in Libby, MT, USA. Previously unreported spirometric results are presented here in relation to exposure and radiographic findings.

4,524 study participants were assigned to one of seven mutually exclusive exposure categories. Associations among radiographic findings, spirometric results and exposure were investigated, along with the effect of a reduction in exposure potential when production was moved to a wet process mill in the mid 1970s.

Spirometry data for the total population by smoking status and age were within the normal range. Prevalence of pleural plaque increased with age, but was lowest in the environmentally exposed group (0.42-12.74\%) and greatest in the W.R. Grace \& Co. mineworkers (20-45.68\%). For males, there was a significant (4.5\%) effect of pleural plaques on forced vital capacity. For W.R. Grace \& Co. workers and household contacts, a reduction in plaque $(0.11$ versus $1.64 \%)$ and in diffuse pleural thickening or costophrenic angle obliteration (1.94 and $0.13 \%$ ) was noted for those exposed after 1976.

These analyses do not support a clinically important reduction in spirometry of this cohort. The 1976 reductions in exposure have led to decrease in radiographic changes.

KEYWORDS: Asbestos-related lung disease, Libby, spirometry, tremolite, vermiculite

ince the 1970s, governmental and nongovernmental researchers have studied the respiratory health effects associated with the vermiculite mine in Libby, MT, USA. The Agency for Toxic Substances and Disease Registry (ATSDR; Atlanta, GA, USA), in cooperation with the Montana Dept of Public Health and Human Services (Helena, MT, USA), released several reports [1-6] revealing important findings about lung disease in the mineworkers that was associated with exposure to vermiculite contaminated with tremolite asbestos. As their primary finding, the ATSDR reported that, in the 20-yr period from 1979 to 1998, the mortality in Libby from asbestosis was 40-80 times higher than expected and lung cancer mortality was $20-30 \%$ greater than expected, when compared with the mortality statistics from the USA and the state of Montana. Mesothelioma mortality was more difficult to assess, due to the inability to have adequate comparison data because of the rarity of this type of cancer. Through these findings, the scientific community alerted the interested parties to health risks associated with working in the Libby mine, resulting in the closure of the mining operation in 1990.

In 2000, the ATSDR initiated a community-based study (Libby Community Environmental Health Project) to investigate reports of respiratory illness and any possible associations with tremolite-contaminated vermiculite exposure. Eligible participants included former W.R. Grace \& Co. workers from Libby and anyone who lived, worked or played in the Libby area for $\geqslant 6$ months prior to December 31, 1990. The medical screening programme consisted of a respiratory health and cigarette smoking questionnaire, simple spirometry and a three-view (erect posterior-anterior (PA), and left and right oblique) chest radiographic examination. The exposure history included inquiries about potential exposure to asbestos or vermiculite,

\section{AFFILIATIONS}

*Division of Pulmonary and Critical Medicine, Stanford University Medical Center, Stanford, CA, \#Section of Pulmonary, Critical Care and Environmental Medicine, Dept of Medicine, Tulane Medical School, and

"Dept of Biostatics, Tulane School of Public Health, New Orleans, LA, USA.

CORRESPONDENCE

D. Weill

Stanford School of Medicine

300 Pasteur Drive

H3143

Stanford

CA 94305-5236

USA

E-mail: dweill@stanford.edu

Received:

March 292010

Accepted after revision:

Nov 262010

First published online:

Dec 222010 
either through having worked for W.R. Grace \& Co. or in other occupations with a potential for asbestos exposure. Other questions addressed household contacts with W.R. Grace \& Co. and/or exposure potentials associated with recreational activities, or domestic use including vermiculite used as loose-fill insulation.

A primary result of the ATSDR report was that $17.8 \%$ of those with radiographs had pleural abnormalities and $0.9 \%$ had interstitial infiltrates [6]. The ATSDR also administered pulmonary function tests (spirometry) to these same individuals, but to our knowledge, these spirometric results have not been previously published. However, concerns over reduced lung function in the Libby population have been presented by WHITEHOUSE [7] in 2004, who concluded that pleural changes in his patient population were associated with progressive lung function loss due to vermiculite exposure.

The purpose of the current study was to investigate the respiratory health of the ATSDR cohort in terms of their pulmonary function results, radiographic findings and exposure pathways. It should be noted that the following analyses were based on ATSDR radiograph interpretations, lung function measures and questionnaires.

\section{METHODS}

The ATSDR database from the Libby Community Environmental Health Project was produced to W.R. Grace \& Co. in US versus W.R. Grace [8]. These data, without any all personal identifiers, was produced pursuant to a subpoena without any restrictions on use and/or privacy and included nine SAS (SAS Institute, Cary, NC, USA) datasets. Eligibility criteria were as previously mentioned and our study included all surveyed individuals 25-90 yrs of age.

A total of 7,307 current and former Libby residents participated in the programme, of who 6,668 received chest radiographs. To focus on exposure from tremolite-contaminated vermiculite, we excluded subjects $(n=1,327)$ with occupations or activities likely to be associated with exposure to traditional, nonvermiculite asbestos-containing materials (hereafter called "traditional asbestos occupations"). This included anyone responding "yes" to any of the following ATSDR queries: "worked as a pipe fitter or steam fitter"; " brake repair person"; "insulator"; "in a job mixing, cutting or spraying asbestos material"; "in any job exposed to asbestos"; or "had asbestos exposure in military". Of the remaining subjects, 4,524 were 25-90 yrs of age and had spirometric test results (fig. 1). Of these, 4,397 had a consensus (two out of three Breaders in agreement) frontal PA [5] chest radiography reading according to the 1980 International Labour Organization (ILO) classification, cigarette smoking data and sufficient information, based on the specific ATSDR exposure pathways queries, in order to allow them to be placed into the seven mutually exclusive exposure categories (table 1). It should be noted that the goal of these qualitative exposure categories was to develop distinct, mutually exclusive categories based on the available information.

Consensus radiographic findings were based on two out of the three ATSDR B-readers' agreement using only the frontal [5] view, as required by the 1980 ILO guidelines. The following radiographic findings were investigated. 1) "Profusion $\geqslant 1 / 0^{\prime}$ ": any two readers reporting any profusion $\geqslant 1 / 0$. 2) "Any plaque": any two readers reporting any diaphragm or wall, or other site plaques, even if the readers did not agree on specifics. 3) "Any diffuse pleural thickening or costophrenic angle obliteration": any two readers reporting any diffuse pleural thickening (DPT) or costophrenic angle obliteration $(\mathrm{CAO})$, even if the readers did not agree on specifics.

Forced expiratory volume in $1 \mathrm{~s}$ (FEV1), forced vital capacity (FVC) and FEV1/FVC \% predicted were computed using the observed values reported by the ATSDR and applying the normative equations developed by KNUDSON et al. [9].

\section{Statistical analysis}

The continuous variables were compared using unpaired ttests and categorical variables were compared using Chisquared tests. Multiple linear regression was used to assess statistical associations between radiographic findings, spirometric test results and exposure categories. All analyses were performed using SAS.

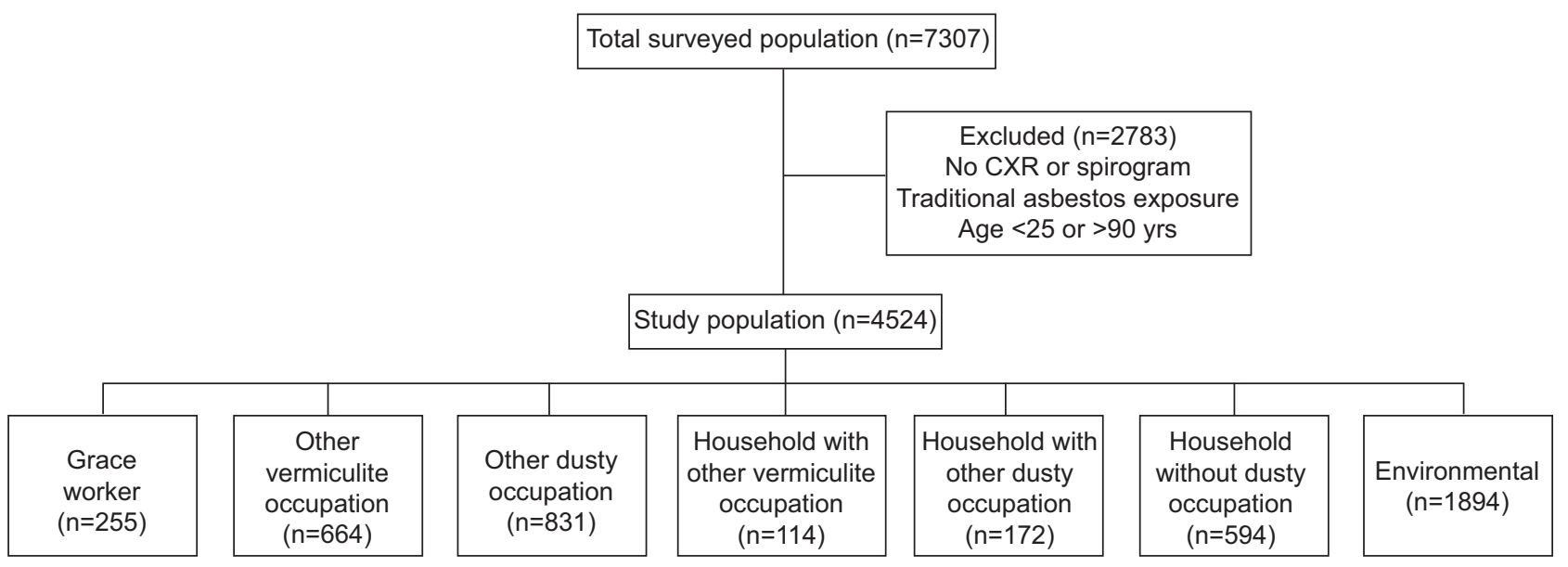

FIGURE 1. Profile of the study population. CXR: chest radiograph. 
TABLE 1 Mutually exclusive exposure categories

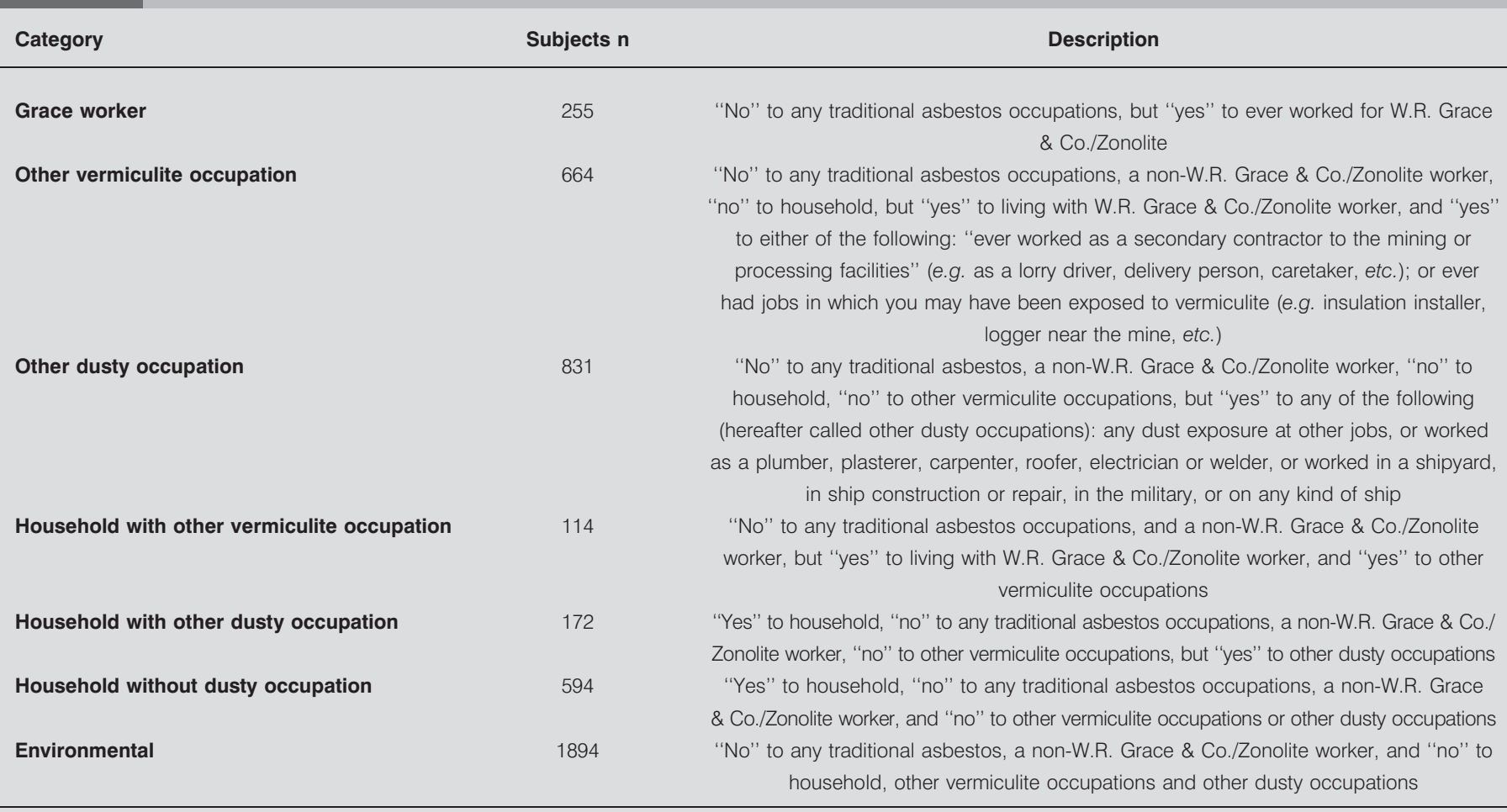

\section{RESULTS}

Spirometric results were investigated for the following age quartiles: 25-40, 41-50, 51-60 and 61-90 yrs. The results of all age quartiles are reported in table 2 , excluding subjects with either evidence of nontremolite asbestos exposure or individuals in whom exposure could not be determined. These results are presented by cigarette smoking status (ever versus never). For all quartiles, reductions in FEV1 and FEV1/FVC \%

TABLE 2 Lung function by age and smoking status

\begin{tabular}{|c|c|c|c|c|c|c|}
\hline Age category & Subjects $n$ & Males \% & BMI $\mathrm{kg} \cdot \mathrm{m}^{-2}$ & FEV1 \% pred ${ }^{\#}$ & FVC $\%$ pred $^{\#}$ & 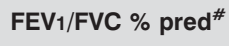 \\
\hline \multicolumn{7}{|l|}{$25-40$ yrs } \\
\hline Never-smokers & 704 & 43.0 & $28.21 \pm 0.23$ & $103.82 \pm 0.52$ & $106.36 \pm 0.51$ & $99.12 \pm 0.29$ \\
\hline All subjects & 1178 & 41.0 & $27.92 \pm 0.17$ & $103.28 \pm 0.41$ & $106.89 \pm 0.39$ & $98.14 \pm 0.23$ \\
\hline \multicolumn{7}{|l|}{$41-50$ yrs } \\
\hline All subjects & 1289 & 41.9 & $28.80 \pm 0.17$ & $100.22 \pm 0.43$ & $104.56 \pm 0.40$ & $97.32 \pm 0.25$ \\
\hline \multicolumn{7}{|l|}{$51-60$ yrs } \\
\hline Ever-smokers & 652 & 44.2 & $29.07 \pm 0.23$ & $90.97 \pm 0.79$ & $98.43 \pm 0.68$ & $92.56 \pm 0.49$ \\
\hline Never-smokers & 492 & 36.6 & $29.33 \pm 0.26$ & $100.84 \pm 0.68$ & $103.91 \pm 0.67$ & $98.71 \pm 0.36$ \\
\hline All subjects & 1144 & 40.9 & $29.18 \pm 0.17$ & $95.22 \pm 0.55$ & $100.79 \pm 0.49$ & $95.21 \pm 0.33$ \\
\hline \multicolumn{7}{|l|}{ All subjects } \\
\hline Ever-smokers & 2504 & 44.5 & $28.60 \pm 0.12$ & $92.12 \pm 0.41$ & $99.35 \pm 0.36$ & $92.76 \pm 0.25$ \\
\hline Never-smokers & 2338 & 38.3 & $28.82 \pm 0.12$ & $101.83 \pm 0.32$ & $103.94 \pm 0.31$ & $99.07 \pm 0.16$ \\
\hline All subjects & 4842 & 41.5 & $28.71 \pm 0.08$ & $96.80 \pm 0.27$ & $101.57 \pm 0.24$ & $95.81 \pm 0.16$ \\
\hline
\end{tabular}

Data are presented as mean \pm SE, unless otherwise stated. BMI: body mass index; FEV1: forced expiratory volume in $1 \mathrm{~s}$; \% pred: \% predicted; FVC: forced vital capacity

\#: using the prediction equations of KNUDSON et al. [9]. 
pred were noted among ever-smokers, as compared with never-smokers, but the lung function for both ever- and neversmokers were within the normal range on average. Furthermore, even higher values were observed in the younger quartiles: usually $>100 \%$ pred, on average.

Also assessed were the presence of radiographic findings in each of the seven exposure categories within each age quartile. The prevalence for profusion of small opacities $(\geqslant 1 / 0)$, plaques with or without calcification, and/or the presence of DPT and/ or CAO, based on the ATSDR/ILO consensus PA readings, are shown in table 3 . The three household exposure groups were combined, as the overall numbers in each group were small and the prevalence of radiographic findings were similar. As expected, the prevalence of all radiographic abnormalities in the Grace worker population was higher than in the other exposure groups, and it increased with age. In addition to the Grace worker group, the prevalence of pleural changes was increased in all of the Household exposure groups and some of the older subjects in other exposure categories.

The effect of specific radiographic findings on FVC \% pred was also assessed. Table 4 shows the effect on average lung function based on specific chest radiograph findings. In this analysis, a comparison of lung function was made between those with the following specific radiographic findings:
1) consensus pleural disease other than DPT or CAO (with or without calcification) and no consensus profusion $\geqslant 1 / 0$; 2) consensus DPT with consensus $\mathrm{CAO}$, but no consensus profusion $\geqslant 1 / 0 ; 3$ ) consensus profusion $\geqslant 1 / 0$ where plaque, DPT, CAO or calcification may be present; and 4) no consensus findings of profusion $\geqslant 1 / 0$, plaque, $\mathrm{DPT}, \mathrm{CAO}$, calcification or effusions.

Here, we excluded subjects who had evidence of nontremolite asbestos. These data show a loss of lung function in subjects with DPT or CAO, and in those with evidence of parenchymal lung disease. Those with pleural findings other than DPT or $\mathrm{CAO}$, or who had no radiographic findings had lung function well within the normal range.

We also investigated what degree of DPT would predict loss of lung function. For this purpose, participants with consensus DPT with CAO were identified. Those with consensus profusion $\geqslant 1 / 0$ and those with consensus effusion were removed, while those with other nontremolite asbestos exposure were retained. The 2000 ILO guidelines were used for classifying DPT by extent and width of the thickening. According to those guidelines, thickening involving $>25 \%$ of the length of the chest wall was designated as extent 2 . A width $>3 \mathrm{~mm}$ was classified as width $a$. Using these two parameters, which indicated more than minimal DPT, the average lung

TABLE 3 Prevalence of chest radiograph findings by age and exposure categories

\begin{tabular}{|c|c|c|c|c|}
\hline \multirow[t]{2}{*}{ Exposure category } & \multirow[t]{2}{*}{ Subjects $n$} & \multicolumn{3}{|c|}{ Prevalence \% } \\
\hline & & Profusion $\geqslant 1 / 0$ & Plaque & DPT and/or CAO \\
\hline \multicolumn{5}{|l|}{ Grace worker } \\
\hline $25-40$ yrs of age & 20 & 0 & 20 & 5 \\
\hline $41-50 \mathrm{yrs}$ of age & 80 & 0 & 26.2 & 5 \\
\hline \multicolumn{5}{|c|}{ Other vermiculite occupation } \\
\hline $25-40$ yrs of age & 122 & 0.8 & 0.8 & 0 \\
\hline $41-50 \mathrm{yrs}$ of age & 192 & 0.5 & 7.8 & 1 \\
\hline $51-60 \mathrm{yrs}$ of age & 160 & 0.6 & 13.7 & 0.6 \\
\hline $61-90 \mathrm{yrs}$ of age & 165 & 0.6 & 24.8 & 8.5 \\
\hline \multicolumn{5}{|c|}{ Other dusty occupation } \\
\hline \multicolumn{5}{|l|}{ Household } \\
\hline $25-40 \mathrm{yrs}$ of age & 224 & 0 & 2.2 & 0 \\
\hline $41-50 \mathrm{yrs}$ of age & 234 & 0 & 11.1 & 0.4 \\
\hline $51-60 \mathrm{yrs}$ of age & 194 & 1 & 20.1 & 1.5 \\
\hline $61-90 \mathrm{yrs}$ of age & 209 & 2.4 & 38.3 & 5.7 \\
\hline \multicolumn{5}{|l|}{ Environmental } \\
\hline $25-40$ yrs of age & 472 & 0 & 0.4 & 0 \\
\hline $41-50 \mathrm{yrs}$ of age & 468 & 0 & 1.9 & 0.2 \\
\hline $51-60 \mathrm{yrs}$ of age & 442 & 0 & 7.7 & 0.9 \\
\hline $61-90 \mathrm{yrs}$ of age & 463 & 1.3 & 12.7 & 2.2 \\
\hline
\end{tabular}


TABLE 4 Chest radiograph findings and forced vital capacity (FVC)

\begin{tabular}{|c|c|c|c|c|c|c|}
\hline Radiographic findings & Subjects $n$ & Age yrs & $\mathrm{BMI} \mathbf{k g} \cdot \mathrm{m}^{-2}$ & Males \% & Ever-smokers \% & FVC $\%$ pred $^{\#}$ \\
\hline $\begin{array}{l}\text { Pleural abnormality excluding DPT, } \\
\text { CAO or profusion } \geqslant 1 / 0\end{array}$ & 482 & $60.07 \pm 0.53$ & $30.30 \pm 0.24$ & 63.50 & 63.69 & $95.63 \pm 0.76$ \\
\hline DPT or CAO excluding profusion $\geqslant 1 / 0$ & 33 & $66.73 \pm 1.85$ & $30.79 \pm 1.25$ & 66.70 & 81.80 & $78.76 \pm 3.64$ \\
\hline Profusion $\geqslant 1 / 0$ & 40 & $67.50 \pm 1.73$ & $28.04 \pm 0.97$ & 70.00 & 77.50 & $82.16 \pm 3.34$ \\
\hline
\end{tabular}

Data are presented as mean $\pm \mathrm{SE}$, unless otherwise stated. BMI: body mass index; \% pred: \% predicted; DPT: diffuse pleural thickening; CAO: costophrenic angle obliteration. ${ }^{*}$ : using the prediction equations of KNUDSON et al. [9].

function was measured after dividing the population into two groups: one group had an extent greater $\geqslant 2$ and had a width $\geqslant a$, and the second group did not meet these criteria. As shown in table 5, the group that met these criteria had a significantly lower FVC than the group not meeting the criteria.

Next, statistically significant effects on FVC \% pred were investigated for specific radiographic findings, cigarette smoking (ever or never), sex, age, body mass index (BMI), exposure category and interactions between these factors. Again, significant interactions were noted between radiographic findings and both cigarette smoking and sex, so individual models were developed for the following categories: never-smoking males, never-smoking females, eversmoking males and ever-smoking females.

With all seven exposure groups combined, significant effects were found for ever-smoking females and for both ever- and never-smoking males. DPT and/or CAO had significant adverse effects on FVC in all smoking and sex combination groups except in never-smoking females. The reductions in FVC $\%$ pred were $6.73 \%$ for ever-smoking females, $9.77 \%$ for ever-smoking males and $23.77 \%$ for never-smoking males. However, the presence of pleural plaques led to a small reduction in FVC in males only (4.2-4.4\%) and, on average, an FVC that was still near $100 \%$ pred. These results are summarised in table 6. We also conducted a similar analysis where we excluded the Grace worker and the household with

\begin{tabular}{|c|c|c|c|}
\hline TABLE 5 & \multicolumn{3}{|c|}{$\begin{array}{l}\text { Diffuse pleural thickening (DPT) and forced vital } \\
\text { capacity (FVC) }\end{array}$} \\
\hline \multicolumn{2}{|c|}{ DPT characteristics ${ }^{\#}$} & Subjects $n$ & FVC $\%$ pred mean \pm SE \\
\hline \multicolumn{2}{|c|}{ Extent $\geqslant 2$ and width $\geqslant a$} & 30 & $76.26 \pm 2.84^{\circ}$ \\
\hline \multicolumn{2}{|c|}{ Extent $<2$ and/or width $<a$} & 23 & $91.98 \pm 3.63$ \\
\hline \multicolumn{2}{|l|}{ All subjects } & 53 & $83.08 \pm 2.48$ \\
\hline
\end{tabular}

$\%$ pred: \% predicted. * : based upon 2000 International Labour Organization guidelines, extent 2 represents $>25 \%$ chest wall involvement and width $a=3 \mathrm{~mm}$. : $\mathrm{p}=0.0006$ vermiculite occupation groups, because preliminary analyses indicated that, of all the exposure categories, only these two were sometimes significantly different from the nonoccupational, nonhousehold contact group in terms of their effect on FVC. However, the results were similar and the same significant radiographic effects were observed.

Also investigated was the effect on prevalence of radiographic findings in the general population due to the closing of the old dry and wet mills in 1974. This resulted in a reduction in the mining operation exposure estimates that sometimes exceeded 100 fibres $\cdot \mathrm{cm}^{-3}$ prior to 1975 to $<1$ fibre $\cdot \mathrm{cm}^{-3}$ after 1976 , based on 8-h time-weighted average job exposure estimates [10]. We again included all individuals $>25$ yrs of age, excluding only those with any reported nontremolite asbestos exposure, Grace workers and those with household exposures from living with an active Grace worker. Therefore, the following individuals were retained: 1) those with only environmental exposure; 2) those reporting "yes" to any dust exposure at other jobs, or working as a plumber, plasterer, carpenter, roofer, electrician or welder, or working in a shipyard, in ship construction or repair, in the military, or on any kind of ship; 3 ) those with other occupations with potential vermiculite exposure who reported "yes" to ever working as a secondary contractor to the mining or processing facilities (e.g. as a lorry driver, delivery person, caretaker, etc.); and 4) those that ever had jobs in which they may have been exposed to vermiculite, but not as a direct employee of W.R. Grace \& Co.

This population was divided into those that had any residential (first year moved into Libby area or Koontenai Valley) or occupational (first year started in any of the types of occupations noted above) exposure prior to 1976, and those that had residential or occupational exposure only after 1976. Table 7 shows the prevalence of profusion, any plaque (diaphragm or wall), and any DPT or CAO, by pre- and post-1976 exposure potential, and by age category. Those shown as "don't know" had insufficient radiographic findings to determine a consensus. Also reported are the proportions of males, smokers and those reporting to have played in piles of vermiculite, and FVC \% pred. For the oldest age group (61$90 \mathrm{yrs}$ ), the reductions were still almost four-fold for plaque, with no consensus readings of DPT or CAO after 1976. It should be noted that $33.44 \%$ of the individuals in the pre- 1976 
TABLE 6 Effect of chest radiograph findings on forced vital capacity \% predicted, adjusting for age, sex, smoking status and body mass index (BMI)

Profusion $\geqslant 1 / 0 \quad$ Plaque with or without calcification

\section{Females}

Never-smokers

Subjects $n$

Intercept

Radiograph

Age

BMI

Ever-smokers

Subjects $n$

Intercept

Radiograph

Age

$\mathrm{BMI}$

Males

Never-smokers

Subjects $n$

Intercept

Radiograph

Age

BMI

Ever-smokers

Subjects $n$

Intercept

Radiograph

Age

BMI
1233

133. $11^{\text {* }}$

NS

-0.32 *

-0.41 *

1116

141.83*

NS

-0.58 *

-0.37 *

684

$116.98^{*}$

NS

NS

$-0.46^{*}$

692

119.92 *

NS

NS

-0.64 *
DPT and/or CAO
1234

$133.14^{*}$

NS

$-0.32^{*}$

$-0.41^{*}$

1127

141.71 *

$-6.73^{*}$

$-0.58^{*}$

$-0.37^{\star}$

685

116.96*

$-23.77^{*}$

NS

$-0.46^{*}$

699

$124.73^{*}$

$-9.77^{*}$

$-0.10^{*}$

$-0.63^{*}$

DPT: diffuse pleural thickening; CAO: costophrenic angle obliteration; NS: nonsignificant. *: $\mathrm{p}<0.05$.

TABLE 7 Prevalence of chest radiograph findings by timing of exposure ${ }^{\#}$

Subjects n Males \% $\quad$ Smokers \% Play in FVC \% pred piles $\% \quad$ mean $\pm S E$

\begin{tabular}{|c|c|c|c|c|c|}
\hline \multicolumn{2}{|c|}{$\begin{array}{c}\text { Profusion } \\
\geqslant 1 / 0 \%\end{array}$} & \multicolumn{2}{|c|}{ Plaque \% } & \multicolumn{2}{|c|}{ DPT or CAO $\%$} \\
\hline No & Yes & No & Yes & No & Yes \\
\hline
\end{tabular}

\section{Before 1976}

25-40 yrs of age

41-50 yrs of age

51-60 yrs of age

61-90 yrs of age

All subjects

\section{After 1976}

25-40 yrs of age

41-50 yrs of age

51-60 yrs of age

61-90 yrs of age

All subjects

$\begin{array}{rr}571 & 42 . \\ 582 & 43.8 \\ 642 & 41 . \\ 777 & 42.3 \\ 2572 & 42 . \\ & \\ 260 & 40.4 \\ 293 & 39.2 \\ 153 & 38.5 \\ 85 & 36.5 \\ 791 & 39.2\end{array}$

$\begin{array}{ll}42.2 & 35.5 \\ 43.8 & 47.6 \\ 41.1 & 54.7 \\ 42.3 & 57.3 \\ 42.4 & 49.6 \\ & \\ 40.4 & 40.8 \\ 39.2 & 47.4 \\ 38.5 & 56.9 \\ 36.5 & 63.5 \\ 39.2 & 48.8\end{array}$

51.1
43.5
29.3
16.3
33.4

25
7.8
5.9
1.2
12.4

$\begin{array}{rr}107.25 \pm 0.56 & 99.8 \\ 103.82 \pm 0.59 & 99.1 \\ 100.92 \pm 0.66 & 97.2 \\ 94.62 \pm 0.72 & 92.5 \\ 101.08 \pm 0.34 & 96.8\end{array}$

0.2

97

94.8

86.8

78.8

78.8

FVC: forced vital capacity; \% pred: \% predicted; DPT: diffuse pleural thickening; CAO: costophrenic angle obliteration. *: excluding non-tremolite asbestos-exposed subjects, Grace workers and household contacts. 
category reported that they had played in piles of vermiculite, compared with $12.39 \%$ in the post-1976 group, introducing the possibility of selection bias. Regardless, the FVC values were $>100 \%$ pred, on average, with similar results noted before and after 1976. All participants had a minimum 10-yr latency between the time they entered the Libby area and the date of their radiograph.

Overall, a more than six-fold reduction in plaque (prevalence reduced from 10.11 to $1.64 \%$ ), and an almost 15 -fold reduction in DPT or CAO (reduced from 1.94 to $0.13 \%$ ) is noted before versus after 1976, respectively. These data are shown in figure 2 .

\section{DISCUSSION}

Our study focused on the previously unreported pulmonary function findings of the ATSDR radiographic screening study. Concerns over reduced lung function in the Libby population have been reported by WHITEHOUSE [7] in 2004, who concluded that pleural changes in his patient population were associated with progressive loss in pulmonary function due to exposure to Libby tremolite and that his patient population was "representative of the population of Libby, Montana." On closer inspection, his population of 123 patients consisted of $86(70 \%)$ former W.R. Grace \& Co. employees, which was not a representative sample of the population of Libby. WHITEHOUSE [7] also reported that the average annual \% pred loss of lung function was 3.2\% for FVC, $2.3 \%$ for total lung capacity and $3.0 \%$ for diffusing capacity of the lung for carbon monoxide, but this was based on only two datapoints over $\sim 3$ yrs on average, of which $19.5 \%$ and $42.3 \%$ of the subjects had $\leqslant 1$ and $\leqslant 2$ yrs of follow-up, respectively.

Our review of the ATSDR data does not support the conclusion that pleural changes are associated with clinically significant reduced lung function. According to PeIPINS [6], 1,183 participants $>25$ yrs of age were categorised as having any pleural abnormality. However, in a more focused analysis, our review of the lung function in the group $(n=482)$ that had pleural plaques but no other radiographic abnormalities indicated that mean FVC was $95.63 \%$ pred.

As noted, our consensus radiographic findings were based on two out of the three ATSDR B-readers agreement using only

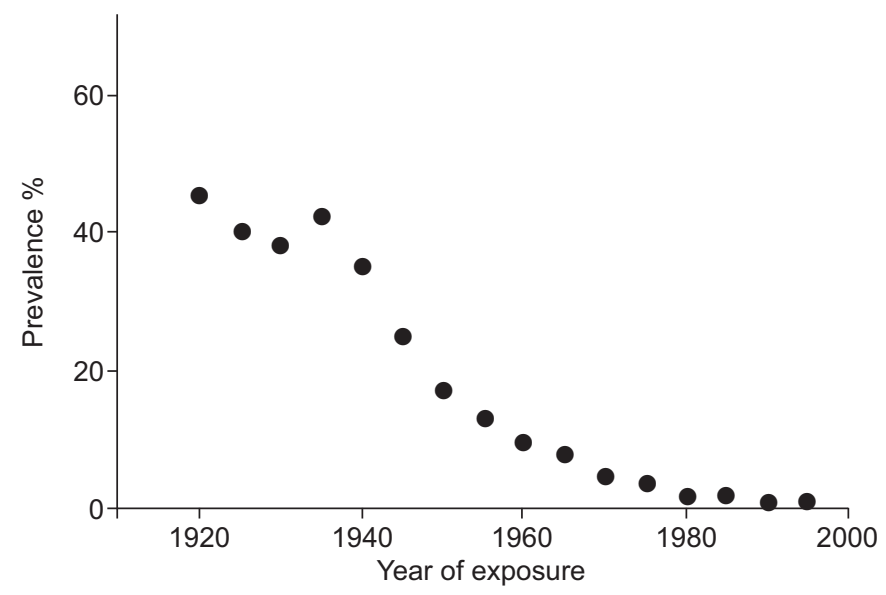

FIGURE 2. Plaque prevalence by the year of initial exposure. the PA view, as required by the 1980 ILO guidelines. This differs in a few significant ways from the method used by PEIPINS et al. [6] with regard to reporting pleural abnormalities associated with the ATSDR study. One of their stated objectives was to "identify and quantify possible asbestosrelated pleural and interstitial abnormalities". Those authors classified study participants as "having a pleural abnormality if two out of three certified B-readers indicated: a) any unilateral or bilateral pleural calcification on the diaphragm, chest wall or other site, or b) any unilateral or bilateral pleural thickening or plaque on the chest wall, diaphragm, or costopherenic angle site, consistent with asbestos-related pleural disease, using the $\mathrm{P}-\mathrm{A}$ view, the oblique views or a combination of those views".

The decision to use oblique views to arrive at judgments on ILO classification items can increase the prevalence of pleural abnormalities over those that would be found using only the PA view. Whether this would also increase the specificity for asbestos causation, as stated by PEIPINS et al. [6], is uncertain. For example, more cases of pleural stripe widening due to subpleural fat (the mean BMI for those categorised as having pleural abnormalities was $30.4 \mathrm{~kg} \cdot \mathrm{m}^{-2}$ ) or companion shadows will be found using obliques, unless the readers strictly adhere to the ILO 2000 guidelines to indicate diffuse thickening only if it extends into the costophrenic angle. This was not a requirement in the 1980 ILO Guidelines that were used by the ATSDR readers, and a failure to apply the current standards could have led to an overestimation of pleural disease prevalence by abnormalities that have no relation to asbestos, or even to disease. This consideration notwithstanding, the use of oblique films in the PEIPINS et al. [6] study renders the results not comparable to published studies that comply with ILO 1980 and 2000 guidelines that support only using the PA view.

Irrespective of the above, findings of PEIPINS et al. [6] associated with the pleural abnormalities are worthy of careful consideration. Males had a much higher risk of developing pleural findings (OR 3.8) as compared with females (OR 1.0) [1-4, 6]. Given the higher rate of occupational exposure to asbestos among males, these findings are not surprising and are further supported by the dose-response relationship described in the ATSDR study between exposure and the development of pleural plaques $[2,4]$. Both of these findings give further support to the premise that asbestos effects were found most strikingly in occupationally (as opposed to environmentally) exposed individuals. Notably, subjects in the other dusty occupations group may have had occupational exposure to asbestos, accounting for some of the noted pleural changes in that exposure group.

In our study of the ATSDR dataset, we investigated the associations between lung function, radiographic findings and exposure, resulting in the following conclusions. 1) The pulmonary function of the screened population as a whole is well within normal limits in all age groups, smoking categories and exposure groups. There was an expected detrimental effect on lung function due to cigarette smoking. 2) In both females and males, and considering smokers and never-smokers, the prevalence of pleural plaques increased with age quartile. As expected, the prevalence of pleural plaques among all age 
groups was much less in the environmental exposure group (range $0.42-12.74 \%$ ), as compared with those that worked at the mine (range $20-45.68 \%$ ), or those who lived with a mine worker (range 1.34-37.67\%). 3) With regard to the effect of pleural plaques on FVC in males, there was a small, probably clinically insignificant reduction of $<4.5 \%$. There was no effect attributable to radiographic findings of plaque seen in females. 4) The closing of the old wet and dry mills at the facility appears to be associated with an overall post-1976 reduction in pleural abnormalities in the general population, resulting in prevalence rates $<2 \%$ for plaque and $<0.2 \%$ for DPT or CAO. 5) DPT is associated with a reduction in FVC, particularly when found to be greater than extent 2 and width $a$.

\section{SUPPORT STATEMENT}

The analysis was funded by W.R. Grace \& Co., but the data upon which the analyses were based were independently collected by the Agency for Toxic Substances and Disease Registry (ATSDR), an agency of the US Department of Health and Human Services.

\section{STATEMENT OF INTEREST}

A statement of interest for D. Weill and for the study itself can be found at www.erj.ersjournals.com/site/misc/statements.xhtml

\section{REFERENCES}

1 Dearwent S, Lewin M, Metcalf S. Mortality in Libby, Montana, 1979-1998. Atlanta, ATSDR, 2001.

2 Agency for Toxic Substances and Disease Registry. Year 2000 medical testing of individuals potentially exposed to asbestoform minerals associated with vermiculite in Libby, Montana: a report to the community. Atlanta, US Dept of Health and Human Services, 2001.

3 Agency for Toxic Substances and Disease Registry. Health consultation on mortality from asbestosis in Libby, Montana for Libby Asbestos site. Atlanta, US Dept of Health and Human Services, 2000.

4 Lybarger J, Lewin M, Miller A, et al. Preliminary findings of medical testing of individuals potentially exposed to asbestoform minerals associated with vermiculite in Libby, Montana: an interim report for community health planning. Atlanta, US Dept of Health and Human Services, 2001.

5 Muravov OI, Kaye WE, Lewin M, et al. The usefulness of computed tomography in detecting asbestos-related pleural abnormalities in people who had indeterminate chest radiographs: the Libby, MT, experience. Int J Hyg Environ Health 2005; 208: 87-99.

6 Peipins LA, Lewin M, Campolucci S, et al. Radiographic abnormalities and exposure to asbestos-contaminated vermiculite in the community of Libby, Montana, USA. Environ Health Perspect 2003; 111: 1753-1759.

7 Whitehouse AC. Asbestos-related pleural disease due to tremolite associated with progressive loss of lung function: serial observations in 123 miners, family members, and residents of Libby, Montana. Am J Ind Med 2004; 46: 219-225.

8 In re W.R. Grace \& Co., et al (2009) Bankr. D. Del. No. 01-01139 (JKF).

9 Knudson RJ, Lebowitz MD, Holberg CJ, et al. Changes in the normal maximal expiratory flow-volume curve with growth and aging. Am Rev Respir Dis 1983; 127: 725-734.

10 Amandus HE, Wheeler R, Jankovic J, et al. The morbidity and mortality of vermiculite miners and millers exposed to tremoliteactinolite: Part I. Exposure estimates. Am J Ind Med 1987; 11: 1-14. 